\title{
Comportamento germinativo de sementes de cultivares de milho sob condições de hipoxia
}

\section{Germinative behavior of seeds of maize cultivars under hypoxia conditions}

\author{
Diego GAZOLA'; Claudemir ZUCARELI²; Mauro César CAMARGO³ \\ ${ }^{1}$ Autor para correspondência. Eng. Agrônomo pós graduando do Programa de Pós-Graduação em Agronomia \\ da Universidade Estadual de Londrina-UEL, gazolad@hotmail.com \\ ${ }^{2}$ Eng. Agr., Dr., Professor adjunto, Departamento de Agronomia - CCA, UEL - CP 6001, CEP:86051-990 - \\ Londrina/PR, claudemircca@uel.br \\ ${ }^{3}$ Enegenheiro agrônomo, UEL. maurocamargo@hotmail.com
}

Recebido em: 05-07-2013; Aceito em: 14-05-2014

\begin{abstract}
Resumo
A diversidade genética existente no milho permite seu cultivo nos mais diversos ambientes. Contudo, o excesso de chuva, em regiões úmidas e quentes, logo após a semeadura, pode prejudicar a germinação por restringir o oxigênio ou causar danos embrionários provocados pela embebição demasiadamente rápida. Deste modo, este trabalho teve por objetivo verificar os efeitos de períodos de hipoxia na germinação de sementes de diferentes cultivares de milho. Foram utilizados três tipos de cultivares, sendo dois híbridos (DKB 787 e AG 8088), uma variedade melhorada (IPR 114) e duas variedades crioulas (Asteca e Caiano) submetidos a 4; 8; 12; 24; 36; 48 e 96 horas de hipoxia, sob temperatura de $25 \stackrel{\circ}{\circ}$, com quatro repetições de 50 sementes. A qualidade inicial das sementes foi caracterizada pelos testes de germinação, de emergência de plântulas no campo, de envelhecimento acelerado e de frio. Após os períodos de hipoxia, as sementes foram submetidas ao teste de germinação com avaliação das porcentagens de plântulas normais, anormais, sementes mortas e massa seca de plântulas. A hipoxia reduz a porcentagem de germinação das sementes e aumenta a porcentagem de plantas anormais em todas as cultivares. As cultivares Asteca e Caiano apresentam menor porcentagem de germinação. O incremento do período de hipoxia causa mortalidade de sementes para as cultivares IPR 114 e DKB 787. As cultivares DBK 787 e AG 8088 apresentam menor massa seca de plântulas e menor sensibilidade às condições de hipoxia que a variedade e as cultivares crioulas.
\end{abstract}

Palavras-chave adicionais: alagamento; encharcamento do solo; tolerância; variedades crioulas; Zea mays.

\begin{abstract}
Maize genetic diversity permits its cultivation under most of the environmental conditions. Excessive rain in hot and humid regions soon after seed sowing may, though, hamper germination due to lack of oxygen or cause damage to the embryo axis due to a very rapid imbibition. So, this study had the objective of verifying the effects of periods of hypoxia on the germination of seeds of several maize cultivars. Three types of maize cultivars were used : two hybrids (DKB 787 and AG 8088), one improved variety (IPR 114), and two landrace varieties (Asteca and Calano) whose seeds were submitted to $4,8,12,24,48$, and 96 hours of hypoxia under a temperature of $25^{\circ} \mathrm{C}$ with four repetitions of 50 seeds. Seed initial quality was evaluated by means of germination, seedling emergence in the field, accelerated aging, and cold test. After the hypoxia treatments, the seeds were submitted to the germination test evaluating the percentage of normal seedlings, abnormal seedlings, dead seeds, and the seedlings dry matter content. Hypoxia reduced seeds germination percentage and increased the percentage of abnormal seedlings in all cultivars. Cultivars Asteca and Caiano presented the lowest germination percentage. Increasing hypoxia duration causes seed death in cultivars IPR 114 and DKB 787. Cultivars DKB 787 and AG 8088 seedlings were the ones with the lowest dry matter content in comparison with the variety and the landrace cultivars.
\end{abstract}

Additional keywords: flooding; landraces; soil flooding; tolerance; varieties; Zea mays. 


\section{Introdução}

O milho, em função dos usos na alimentação humana e animal, potencial produtivo, composição química e valor nutritivo, constitui-se em um dos mais importantes cereais cultivados e consumidos no mundo (FANCELLI \& DOURADO NETO, 2008; VELOSO et al., 2006). Em virtude de sua localização, o Brasil apresenta condições que permitem que o milho seja cultivado em quase toda sua área agrícola (POTTKER, 2000), sendo um dos maiores produtores mundiais desse ceral. $\mathrm{Na}$ safra de 2013/2014, a produção brasileira de milho foi de, aproximadamente, 78 milhões de toneladas, sendo os Estados de Mato Grosso, Paraná e Minas Gerais, os maiores produtores. Contudo, a produtividade média brasileira de milho da safra de 2013 foi de 5,10 t ha ${ }^{-1}$ (CONAB, 2013), enquanto em condições experimentais, geralmente, este valor é superior a 10 t ha $^{-1}$ (SANGOl et al., 2007).

Embora altamente produtivo, vários fatores atuam reduzindo a produtividade da cultura, como temperaturas desfavoráveis, déficiti hídrico, pragas, geadas, deficiência nutricional e encharcamento do solo. O excesso de chuva em algumas regiões úmidas e quentes, logo após a semeadura, pode ser prejudicial à germinação (DANTAS et al., 2000). Segundo KHOSRAVI \& ANDERSON (1990), tanto a submersão das sementes em água, em condições de laboratório, quanto o encharcamento do solo, em condições de campo, reduzem ou impedem a germinação e a emergência de plântulas, comprometendo o estabelecimento do estande.

A produtividade do milho é influenciada pelo arranjo espacial das plantas no campo, definindo pelo estande adequado bem como pelo espaçamento entre as linhas e a uniformidade de desenvolvimento das plantas (EMYGDIO \& PEREIRA, 2006). Um arranjo ideal é aquele que possui uma distribuição uniforme das plantas na linha, o que é garantido pela adequada emergência e pelo estabelecimento das plântulas, resultando em eficiente utilização da luz, água e nutrientes e, consequentemente, favorecendo a produtividade (FEPAGRO et al., 2005).

Solos com altos níveis de compactação, drenagem deficiente e sujeitos a alto regime pluvial ou a sistemas de irrigação inadequados apresentam problemas de aeração, que resultam em condições de hipoxia (baixa pressão de oxigênio) ou anoxia (ausência de oxigênio) no ambiente radicular. Plantas que se desenvolvem nessas condições têm seu desenvolvimento comprometido e os crescimentos vegetativo e reprodutivo reduzidos, de forma que a permanência prolongada sob deficiência de oxigênio pode levá-las à morte (ALVES, 2002), comprometendo o estande e o arranjo de plantas no campo.

Dentre os fatores externos que mais afetam o processo de germinação, sem dúvida, a água é determinante. A primeira condição para a germinação de uma semente não dormente é a disponibilidade de água para a reidratação. O aumento das atividades respiratórias da semente a um nível capaz de sustentar o crescimento do embrião, com fornecimento suficiente de energia e substâncias orgânicas, depende do aumento do grau de hidratação de seus tecidos (POPINIGIS, 1985; CARVALHO \& NAKAGAWA, 2012). Ainda segundo esses autores, o oxigênio é também fator fundamental para o processo germinativo, pois participa da degradação das substâncias de reserva da semente para o fornecimento de nutrientes e energia para o desenvolvimento do eixo embrionário.

A escolha da cultivar a ser utilizada é um dos principais fatores de sucesso para a cultura do milho (ARAÚJO \& NASS, 2002), visto que existem genótipos que são adequados às diferentes condições climáticas brasileiras (EMBRAPA, 2012), podendo até, por exemplo, possuir tolerância ao déficit hídrico (PIMENTEL, 1999; CÂMARA et al., 2007), ao alagamento (ALVES et al., 2002) ou à incidência de algumas doenças (VON PINHO et al., 2001; SILVA et al., 2002).

Atualmente, estão disponíveis no mercado diversas cultivares altamente produtivas; contudo, ainda existe deficiência na disponibilidade de materiais genéticos para condições desfavoráveis de cultivo como o encharcamento do solo. Uma fonte de variabilidade genética importantíssima para a busca de cultivares resistentes e/ou tolerantes a condições climáticas desfavoráveis são os materiais crioulos, que apesar da baixa produtividade, são altamente adaptados a condições adversas (PATERNIANI et al., 2000; ARAÚJO \& NASS, 2002).

A diversidade genética existente no miIho permite seu cultivo nos mais diversos ambientes. Além disso, o milho é a espécie vegetal geneticamente mais estudada $e$, consequentemente, a herança de inúmeros caracteres e seu genoma são bem conhecidos (NASS \& PATERNIANI, 2000). Alguns trabalhos relatam a existência de variabilidade entre cultivares de milho em relação ao alagamento (DANTAS et al., 2000; ALVES et al., 2002). VITORINO et al. (2001) constataram que a variedade Saracura teve sobrevivência de $80 \%$, quando submetida a $72 \mathrm{~h}$ de alagamento, demonstrando certa tolerância desse material ao estresse causado pelo excesso hídrico.

Assim, o presente trabalho teve por objetivo verificar os efeitos de períodos de hipoxia no processo germinativo de sementes de diferentes tipos de cultivares de milho. 


\section{Material e métodos}

O experimento foi conduzido no Laboratório de Análises de Sementes da Universidade Estadual de Londrina, Londrina-PR. Foram utilizadas sementes de três tipos de cultivares de milho, sendo dois híbridos comerciais (DKB 787 e AG 8088), uma variedade melhorada (IPR 114) e duas variedades crioulas (Asteca e Caiano) que foram obtidas junto a produtores familiares de Imbaú-PR.

As sementes de todas as cultivares foram caracterizadas quanto à qualidade fisiológica inicial, por meio dos seguintes testes:

a) Teor de água: realizado com quatro repetições de 25 sementes para cada cultivar, colocados em estufa regulada á temperatura de $105^{\circ} \mathrm{C} \pm 3^{\circ} \mathrm{C}$, por 24 horas (BRASIL, 2009).

b) Germinação: realizado com quatro repetições de 50 sementes, em rolos de papel toalha, à temperatura de $25^{\circ} \mathrm{C}$, seguindo os critérios estabelecidos nas Regras para Análise de Sementes (BRASIL 2009).

C) Emergência de plântulas no campo: realizado com quatro repetições de 50 sementes de cada cultivar. Foram semeadas em sulcos de dois metros de comprimento, espaçados de meio metro entre si, à profundidade de 3 a $5 \mathrm{~cm}$. A contagem das plântulas emergidas foi realizada uma única vez, aos 21 dias após a semeadura. O solo utilizado para a condução do experimento foi do tipo Nitossolo Vermelho eutroférrico latossólico (EMBRAPA, 2006), cuja umidade foi mantida por meio de irrigações realizadas sempre que necessário e na mesma quantidade para todos os tratamentos.

d) Envelhecimento acelerado: realizado com quatro repetições de 75 sementes distribuídas sobre bandeja de tela de alumínio, fixada no interior do gerbox, contendo $40 \mathrm{~mL}$ de água e mantida a $42^{\circ} \mathrm{C}$ por $72 \mathrm{~h}$ (DIAS \& BARROS, 1995).

e) Teste de frio: realizado com quatro repetições de 50 sementes, à temperatura de $10^{\circ} \mathrm{C}$, por sete dias, e depois transferidas para germinador a $25^{\circ} \mathrm{C}$ por quatro dias, realizandose uma única contagem das plântulas normais (DIAS \& BARROS, 1995).

Para a condução e instalação do experimento, foram utilizadas quatro repetições de 50 sementes de cada cultivar, tomadas aleatoriamente, que foram colocadas em copos de plástico $(200 \mathrm{~mL})$ e submersas em $10 \mathrm{~mL}$ de água destilada por períodos de $4 ; 8 ; 12 ; 24 ; 36 ; 48$ e $96 \mathrm{~h}$ sob temperatura de $25^{\circ} \mathrm{C}$. Para evitar a proliferação de fungos e bactérias durante 0 período de hipoxia, foi adicionado na solução micostatina $(0,2 \%)$ e $50 \mathrm{mg}$ de Benzilpenicilina Potássica por $\mathrm{mL}$ de água. Após os períodos de alagamento, as sementes foram submetidas às seguintes avaliações:

a) Germinação: quatro repetições de 50 sementes, instaladas em rolos de papel toalha germistest e colocadas para germinar à temperatura de $25^{\circ} \mathrm{C}$. As avaliações foram realizadas no quarto e no sétimo dia após a instalação do teste de germinação, com contagens de plântulas normais, anormais e sementes mortas (BRASIL, 2009).

b) Massa seca de plântulas: obtidas pela pesagem da parte aérea e das raízes das plântulas normais do teste de germinação na segunda contagem. Elas foram colocadas para secar em estufa a $65^{\circ} \mathrm{C}$ até massa constante.

Os dados foram submetidos à análise de variância pelo teste $\mathrm{F}$, e as médias, comparadas pelo teste de Tukey, a 5\% de probabilidade de erro. Os dados referentes aos períodos de hipoxia foram submetidos à análise de regressão polinomial.

\section{Resultados e discussão}

Os resultados da avaliação da qualidade fisiológica inicial das sementes das cultivares de milho utilizadas demonstraram semelhança entre os lotes utilizados (Tabela 1). Foram observadas diferenças significativas apenas no teor de água das sementes, com menores valores para os dois híbridos comerciais utilizados (DKB 787 e $A G$ 8088), e na porcentagem de germinação após o teste de envelhecimento acelerado, em que o híbrido AG 8088 apresentou porcentagem de plântulas normais inferior à das demais cultivares (Tabela 1 ).

Nas características germinação e plantas anormais, não foram observadas interações entre os fatores cultivares e períodos de hipoxia, apenas efeito isolado significativo de cada fator (Tabela 2). As cultivares DKB 787 e a IPR 114 apresentaram germinação média de 94,5 e 94,4\%, respectivamente, e as cultivares Asteca e a Caiano apresentaram médias de $91,1 \%$ e $91,8 \%$, respectivamente, sendo que os dois grupos diferiram estatisticamente.

A diferença observada entre os tipos de cultivares pode estar associada ao processo de seleção artificial de melhoramento a que as cultivares comercias foram submetidas, diferentemente das variedades crioulas. A conservação das variedades crioulas é realizada pelos agricultores que estão comprometidos com a atividade de multiplicação, seleção e uso de suas sementes, com base em conhecimentos tradicionais empíricos, que são transmitidos ao longo de gerações. Neste processo de seleção de plantas, a falta de controle sobre as variações do ambiente de cultivo dificulta a identificação de bons genótipos, pois ela é feita por meio da avaliação fenotípica de plantas individuais (OGLIARI et al., 
2013). Ainda para efeito de cultivar, observa-se que, na característica plantas anormais, as cultivares AG 8088 e a Caiano apresentaram médias de $4,1 \%$ e $3,8 \%$, respectivamente, diferindo da cultivar IPR 114, que apresentou média de 2,2\%.

Embora a constatação de ajuste linear significativo $(p<0,05)$ para os períodos de hipoxia nas variáveis germinação e plantas anormais (Figura 1), os ajustes não explicam de maneira adequada os resultados, como pode ser constatado nos baixos valores de $\mathrm{R}^{2}$. Esse comporta- mento deve-se, provavelmente, aos intervalos avaliados que não foram equidistantes, pois houve maiores alterações para as duas variáveis no período entre 48 a 96 h, último intervalo avaliado. Dessa forma, para a determinação precisa do período de hipoxia tolerado pelas sementes de milho, faz-se necessário o estudo de intervalos menores de submersão em períodos acima de 48 horas.

Tabela 1 - Qualidade fisiológica inicial das sementes das cultivares de milho utilizadas no experimento. Initial quality of the seeds of the cultivars used in the experiment.

\begin{tabular}{|c|c|c|c|c|c|}
\hline \multirow[t]{2}{*}{ Cultivares } & Germinação & Teste de frio & $\begin{array}{c}\text { Emergência no } \\
\text { campo }\end{array}$ & $\begin{array}{l}\text { Envelhecimento } \\
\text { acelerado }\end{array}$ & Teor de água \\
\hline & \multicolumn{5}{|c|}{ } \\
\hline IPR 114 & $96 \mathrm{a}$ & $95 \mathrm{a}$ & $97 \mathrm{a}$ & $96 \mathrm{a}$ & $14,5 \mathrm{a}$ \\
\hline Asteca & $96 \mathrm{a}$ & $96 \mathrm{a}$ & $97 \mathrm{a}$ & $96 \mathrm{a}$ & $14,2 \mathrm{a}$ \\
\hline Caiano & $95 \mathrm{a}$ & $95 \mathrm{a}$ & $95 a$ & $97 \mathrm{a}$ & $14,8 \mathrm{a}$ \\
\hline DKB 787 & $96 \mathrm{a}$ & $99 a$ & $97 \mathrm{a}$ & $89 a$ & $12,3 b$ \\
\hline AG 8088 & $95 \mathrm{a}$ & $94 \mathrm{a}$ & $98 \mathrm{a}$ & $88 \mathrm{~b}$ & $12,8 \mathrm{~b}$ \\
\hline CV (\%) & 3,12 & 2,63 & 4,12 & 4,32 & 4,33 \\
\hline
\end{tabular}

Médias seguidas pela mesma letra na coluna não diferem entre si, pelo teste de Tukey, a 5\% de probabilidade.

Tabela 2 - Plantas normais da primeira contagem (PNPC), germinação (GER); plantas anormais (PA), sementes mortas (SM), massa seca da parte aérea (MSPA), massa seca da raiz (MSR) e massa seca total (MST) de plântulas após diferentes períodos de hipoxia em sementes de cultivares de milho. Analysis of variance results of normal seedlings in the first count (PNPC), germination (GER), abnormal seedlings (PA), dead seeds (SM), seedling aerial part dry matter (MSPA), roots dry matter (MSR), and seedling total mass (MST) following several periods of hypoxia.

\begin{tabular}{|c|c|c|c|c|c|c|c|}
\hline Valor $\mathrm{F}$ & PNPC & GER & PA & SM & MSPA & MSR & MST \\
\hline Cultivar (C) & $6,0^{*}$ & $5,5^{\star}$ & $3,7^{*}$ & $3,7^{*}$ & $261,2^{*}$ & $236,4^{*}$ & $408,9^{*}$ \\
\hline Período de hipoxia $(\mathrm{P})$ & $31,2^{*}$ & $57,9^{*}$ & $25,8^{*}$ & $28,1^{*}$ & $23,8^{*}$ & $18,0^{*}$ & $28,7^{*}$ \\
\hline $\mathrm{C} \times \mathrm{P}$ & $5,4^{*}$ & $1,4 \mathrm{~ns}$ & $1,3 \mathrm{~ns}$ & $1,6^{*}$ & $2,6^{*}$ & $2,8^{*}$ & $3,23^{*}$ \\
\hline CV (\%) & 5,4 & 3,6 & 63,7 & 76,9 & 6,8 & 7,8 & 5,6 \\
\hline \multicolumn{8}{|l|}{ Cultivares } \\
\hline IPR 114 & 92,0 & $94,4 \mathrm{a}$ & $2,2 \mathrm{~b}$ & 3,3 & 1,7 & 2,4 & 4,1 \\
\hline Asteca & 89,3 & $91,1 \mathrm{~b}$ & $2,8 a b$ & 5,2 & 1,6 & 2,5 & 4,1 \\
\hline Caiano & 88,8 & $91,8 \mathrm{~b}$ & $3,8 \mathrm{a}$ & 4,3 & 1,5 & 2,2 & 3,8 \\
\hline DBK 787 & 91,6 & $94,5 \mathrm{a}$ & $2,8 a b$ & 2,6 & 1,1 & 1,5 & 2,6 \\
\hline AG 8088 & 86,8 & $92,7 a b$ & $4,1 \mathrm{a}$ & 3,1 & 1,0 & 1,6 & 2,8 \\
\hline \multicolumn{8}{|l|}{ Período (h) } \\
\hline 4 & 92,2 & 96,6 & 1,6 & 1,8 & 1,3 & 2,2 & 3,5 \\
\hline 8 & 88,4 & 95,5 & 2,9 & 1,6 & 1,4 & 2,1 & 3,4 \\
\hline 12 & 89,1 & 92,1 & 3,4 & 4,5 & 1,4 & 2,1 & 3,5 \\
\hline 24 & 92,6 & 95,6 & 2,2 & 2,2 & 1,5 & 2,2 & 3,6 \\
\hline 36 & 93,2 & 94,9 & 2,4 & 2,7 & 1,5 & 2,2 & 3,7 \\
\hline 48 & 95,2 & 95,6 & 2,1 & 2,3 & 1,5 & 2,1 & 3,6 \\
\hline 96 & 76,9 & 80,2 & 8,6 & 11,2 & 1,2 & 1,8 & 3,0 \\
\hline
\end{tabular}



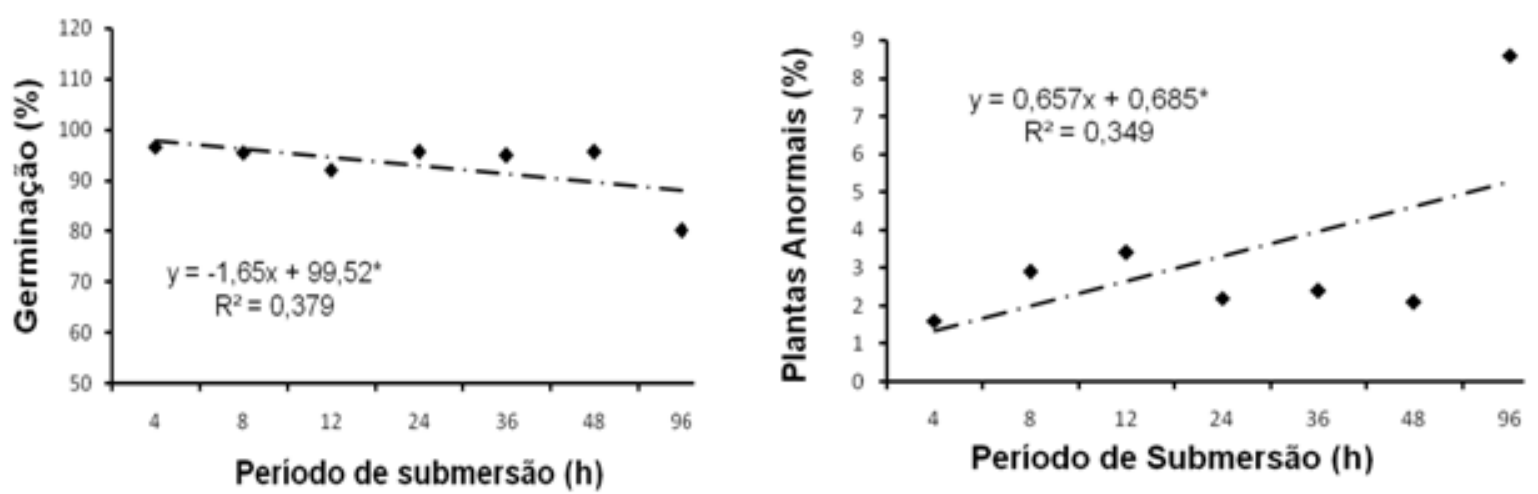

${ }^{(*)}-$ significativos a $5 \%$ de probabilidade, pelo teste $t$.

Figura 1 - Médias das cultivares IPR 114, Asteca, Caiano, DBK 787 e AG 8088 para germinação (\%) e para plantas anormais (\%), em função dos períodos de hipoxia. Germination (\%) and abnormal seedlings (\%) of seeds of maize cultivars IPR 114, Asteca, Caiano, DKB 787, and AG 8088 as influenced by periods of hypoxia.

$\mathrm{Na}$ germinação, todas as cultivares foram prejudicadas com o aumento do tempo de submersão da semente. Esses resultados podem ser explicados pelo estresse hídrico ocasionado, que geralmente atua diminuindo a velocidade e a porcentagem de germinação das sementes. $O$ excesso de água geralmente provoca decréscimo na germinação, visto que impede a penetração do oxigênio e reduz todo o processo metabólico resultante (MORTELE et al., 2006), ou seja, causa ação inibitória na fase bioquímica da fotossíntese (ROMERO et al., 2003). O alagamento e a submersão são fatores de estresses abióticos que afetam o desenvolvimento das plantas e, juntamente com a seca, salinidade e altas temperaturas, constituem os principais determinantes para a distribuição das espécies vegetais no mundo (VISSER et al., 2003).

A porcentagem de plântulas normais na primeira contagem (PNPC), de sementes mortas (SM), massa seca da parte aérea (MSPA) e massa seca da raiz (MSR), e a massa seca total (MST) foram influenciadas significativamente pela interação dos fatores tempo e cultivares (Figura 2).

Para a porcentagem de plantas normais na primeira contagem (Figura $2 \mathrm{~A}$ ), o modelo quadrático foi $\mathrm{O}$ ajustado aos resultados, e os pontos de máxima das cultivares para esta variável ocorreram entre 32 e 49 horas de hipoxia. Durante o processo germinativo, a água atua como agente estimulador e controlador, uma vez que promove o amolecimento do tegumento, favorecendo a penetração do oxigênio, o aumento do volume do embrião e dos tecidos de reserva (VAZ-DE-MELO et al., 2012).

DANTAS et al. (2000) verificaram que, para a cultivar de milho AL 30 , após 24 horas de alagamento, houve decréscimo de aproximadamente $40 \%$ nas plântulas normais por ocasião da primeira contagem. Nos resultados deste estudo, em períodos maiores que 24 horas de submersão, houve efeito positivo no processo germinativo para as cultivares, com menor intensidade para o AG 8088.

A redução na velocidade de germinação avaliada pela porcentagem de germinação na primeira contagem pode estar associada ao estresse proporcionado pela inundação, uma vez que há diminuição e/ou falta de oxigênio e, consequentemente, acúmulo de substâncias tóxicas e diminuição da absorção de nutrientes (CHEN et al., 2002). Quando as cultivares são submetidas a condições de estresse, essas direcionam seu metabolismo a contornar essas condições, com isso o gasto energético é maior com relação à adaptação a esse estresse do que à germinação propriamente dita (VAZ-DE-MELO et al., 2012).

Para a porcentagem de sementes mortas (Figura 2B), as cultivares Asteca, Caiano e AG 8088 não foram significativamente alteradas pelo tempo de submersão. A IPR 114 apresentou aumento linear com o aumento do período de hipoxia, e a DBK 787 apresentou número mínimo de sementes mortas no período de $34 \mathrm{~h}$ de submersão. Quando as sementes são submetidas a metabolismo anaeróbio, as sementes produzem 0 acetaldeído e o etanol (CRAWFORD, 1978), substâncias essas que são tóxicas às sementes e plantas, que podem contribuir para a morte das sementes. Da mesma forma, $\mathrm{O} \mathrm{CO}_{2}$ liberado no meio de inundação inibe a germinação (KIDD, 1914; EYSTER, 1940; CERWICK et al., 1995). Alguns autores, no entanto, acreditam que não há inibição da germinação devido ao acúmulo destas substâncias, que ocorreriam em níveis muito baixos para provocar fitotoxidade (VAN TOAl et al., 1988; MARTIN et al., 1991). 


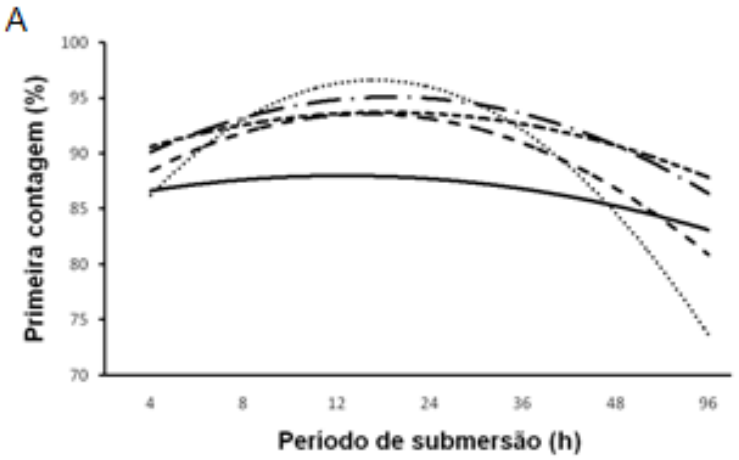

-. IPR 114 - - Asteca ........ Caiano --..-DKB 787 - AG 8088

I PR $114 \mathrm{y}=-0,0046 \mathrm{x}^{2}+0,3659 \mathrm{x}+89,1298^{\circ} \mathrm{R}^{s}=0,85$ Asteca $\mathrm{y}=-0,0053 \mathrm{x}^{2}+0,3885 \mathrm{x}+87,1849^{\circ} \mathrm{R}^{2}=0,81$ Cai and $Y=-0,0065 x^{2}+0,4123 x+88,1036^{*} R^{2}=0,98$ DKB $787 \mathrm{y}=-0,0038 \mathrm{x}^{2}+0,3061 \mathrm{x}+89,0811^{*} \mathrm{R}^{s}=0,65$ AG $8088 \mathrm{y}=-0,0032 \mathrm{x}^{5}+0,2487 \mathrm{x}+84,5722^{*} \mathrm{R}^{s}=0,53$

C

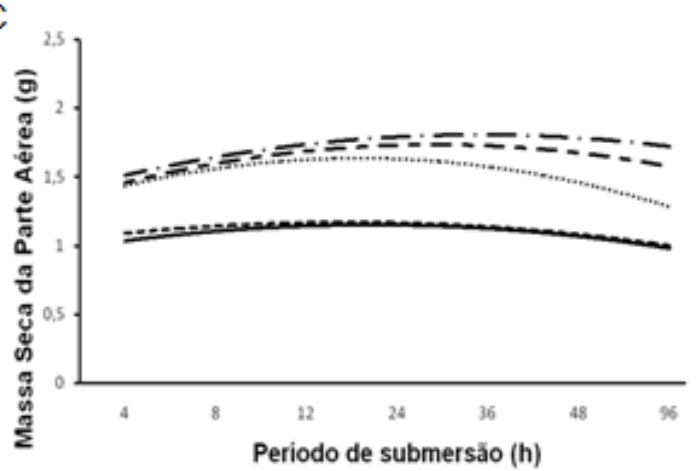

-. IPR 114 - - Asteca ....... Caiano .....DKB 787 -AG 8088

I PR $114 \mathrm{y}=-0,0001 \mathrm{x}^{5}+0,0179 \mathrm{x}+1,4652^{*} \mathrm{R}^{\mathrm{s}}=0,85$ Asteca $\mathrm{y}=-0,0001 \mathrm{x}^{5}+0,0133 \mathrm{x}+1,4233^{*} \mathrm{R}^{2}=0,94$ Caiano $\mathrm{Y}=-0,0001 \mathrm{x}^{2}+0,0071 \mathrm{x}+1,4755^{*} \mathrm{R}^{2}=0,97$ DBK $787 \mathrm{Y}=-0,0000 \mathrm{x}^{5}+0,0059 \mathrm{x}+1,0732^{*} \mathrm{R}^{s}=0,84$ AG $8088 \mathrm{y}=-0,0000 \mathrm{x}^{s}+0,0037 \mathrm{x}+1,0647^{\circ} \mathrm{R}^{s}=0,75$
B

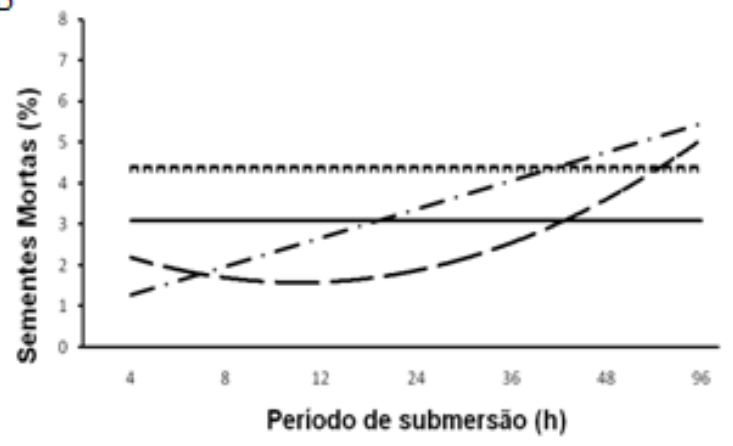

- .IPR 114 -....Asteca …... Caiano - -DKB 787 - AG 8088

I PR $114 \mathrm{Y}=0,0611 \mathrm{x}+1,3650^{\circ} \mathrm{R}^{s}=0,59$

DKB $787 \mathrm{y}=0,0016 \mathrm{x}^{2}-0,1104 \mathrm{x}+3,1226^{*} \mathrm{R}^{\mathrm{s}}=0,57$

Asteca, média $=4,4 \mathrm{~g}$

Caiang.média $=4,3 \mathrm{~g}$

AG $80 \% \&$ méclia $=3,2 \mathrm{~g}$

\section{D}

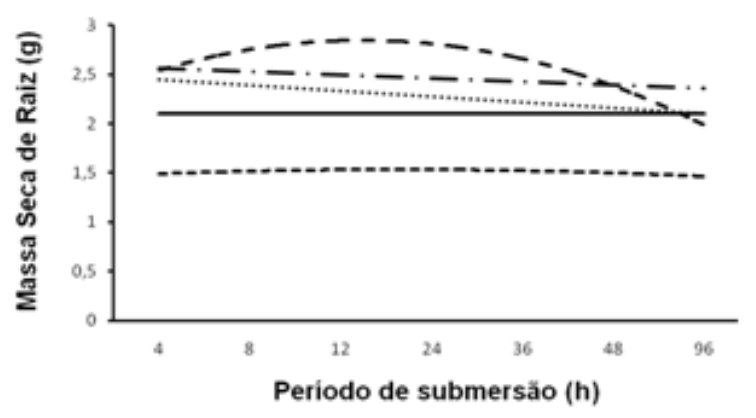

- -IPR 114 - - Asteca ….... Caiano ----DKB 787 - AG 8088

IPR $114 \mathrm{y}=-0,0035 \mathrm{x}+2,5761^{\circ} \mathrm{R}^{\mathrm{s}}=0,45$

Asteca $y=-0,0001 x^{2}+0,0102 x+2,6191^{*} R^{s}=0,97$

Caiang $\mathrm{y}=-0,0052 \mathrm{x}+2,4432^{\circ} \mathrm{R}^{2}=0,68$

DKB $787 \mathrm{y}=-0,0000 \mathrm{x}^{2}+0,0029 \mathrm{x}+2,3365^{*} \mathrm{R}^{s}=0,81$ AG 8088 média $=1,67 \mathrm{c}$

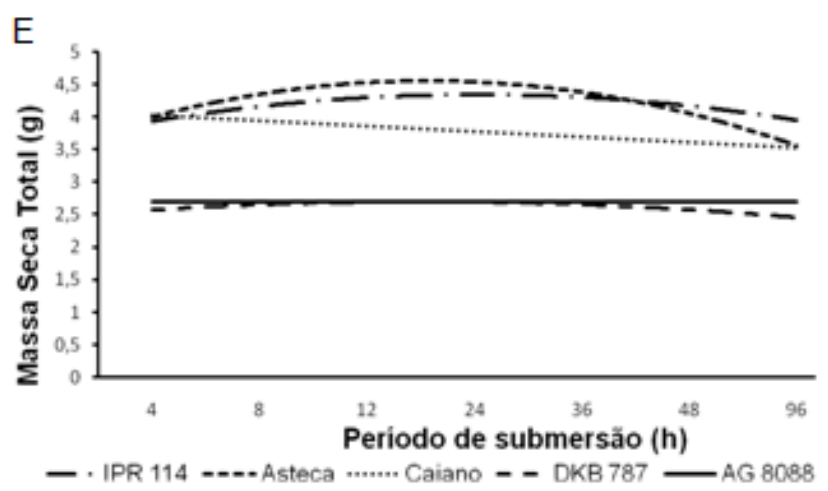

IPR $114 \mathrm{Y}=-0,0002 \mathrm{x}^{5}+0,0255 \mathrm{x}+3,8970^{*} \mathrm{R}^{\varepsilon}=0,82$

Asteca $\mathrm{Y}=-0,0003 \mathrm{x}^{5}+0,0235 \mathrm{x}+4,0825^{*} \mathrm{R}^{s}=0,97$

Caiang $y=-0,0084 x+4,0532^{\circ} R^{2}=0,67$

DKB $787 y=-0,0001 x^{2}+0,0110 x+2,5318^{*} R^{s}=0,78$

AG 8088 , média $=2,70 \mathrm{~g}$

${ }^{(*)}-$ significativos a $5 \%$ de probabilidade, pelo teste $t$.

Figura 2 - (A) - Plântulas normais na primeira Contagem; (B) - sementes mortas; (C) - massa seca da parte aérea; (D) - massa seca de raiz, e $(E)$ - massa seca total de plântulas após diferentes períodos de hipoxia de sementes de diferentes cultivares de milho. (A) Normal seedlings in the first count, (B) dead seeds, (C) seedling aerial part dry matter, (D) root dry matter, and (E) seedling total dry matter after several periods of hypoxia. 
Assim, pode-se inferir que as substâncias tóxicas, possivelmente produzidas em condições de alagamento, causam a morte das sementes e que a cultivar IPR 114 se mostrou mais sensível aos efeitos dessas substâncias.

Para a massa seca da parte aérea (Figura $2 \mathrm{C}$ ), a menor resposta foi a da variedade DBK 787, com valor máximo de $1,2 \mathrm{~g}$ com $34 \mathrm{~h}$ de submersão. Já a IPR 114 obteve a maior massa seca de parte aérea: $2,2 \mathrm{~g}$ com imersão de $89 \mathrm{~h}$.

A cultivar Caiano apresentou maior acúmulo de massa seca em raízes no tempo de $18 \mathrm{~h}$ (Figura 2D), com 2,3 g, enquanto as cultivares IPR 114, DBK 787 e Asteca, apresentaram reposta máxima nos tempos de 38; 42 e $51 \mathrm{~h}$ com 2,5; 1,5 e $2,9 \mathrm{~g}$, respectivamente. Houve variação de massa seca entre as cultivares quando relacionada com o período de hipoxia. $O$ mesmo foi observado por DANTAS et al. (2000) para massa seca de raiz.

As cultivares crioulas Asteca e Caiano, e a variedade IPR 114 tiveram maior variação de massa seca em condições de hipoxia que os híbridos comerciais. Segundo FERREIRA et al. (2008), a maioria dos estudos com variedades de milho crioulo refere-se a ensaios de competição e caracterização que revelam o potencial dessas, pois apresentam desempenho semelhante ou até superior às cultivares comerciais e híbridas, principalmente em condições rústicas de cultivo.

Para a massa seca total, os menores períodos de acúmulo foram ser observados para a variedade Asteca, com $39 \mathrm{~h}$ de submersão, com 4,5 g. A DBK 787 e IPR 114 obtiveram reposta máxima em 55 e 64 h, já a Caiano apresentou ajuste linear, sendo prejudicada com o aumento do tempo de hipoxia. O maior tempo de hipoxia afeta negativamente o acúmulo de massa seca nas cultivares, fato associado à diminuição do crescimento de alguns órgãos, durante o alagamento, sendo uma estratégia para economizar energia e manter um funcionamento mínimo do metabolismo nas regiões mais afetadas pela hipoxia (BATISTA et al., 2008).

Apesar de serem fonte de grande variabilidade genética e de possíveis genótipos de interesse agronômico (NASS \& PATERNIANI, 2000), as variedades crioulas Asteca e Caiano não apresentaram características positivas em relação aos períodos de hipoxia, apresentando resultados inferiores às demais.

A justificativa para investimento em termos de melhoramento nas populações crioulas de baixa produção seria a presença de genes específicos de interesse, especialmente com relação aos estresses bióticos e abióticos importantes na cultura (ARAÚJO \& NASS, 2002). Por isso, fazem-se necessários maiores estudos acerca da identificação de possíveis genes para serem utilizados em programas de melhoramento.

\section{Conclusões}

A hipoxia reduz a germinação das sementes e aumenta a porcentagem de plantas anormais em todas as cultivares. As cultivares crioulas Asteca e Caiano apresentam menor porcentagem de germinação.

O incremento do período de hipoxia causa mortalidade de sementes para as cultivares IPR 114 e DKB 787.

As cultivares DBK 787 e AG 8088 apresentam menor massa seca de plântulas e menor sensibilidade às condições de hipoxia que a variedade e as cultivares crioulas.

\section{Referências}

ALVES, J. D.; MAGALHÃES, M. M.; GOULART, P. F. P.; DANTAS, B. F.; GOUVÊIA, J. A.; PURCINO, R. P; MAGALHÃES, P. C.; FRIES, D. D.; DO LIVRAMENTO, D. E.; MEYER, L. E.; SEIFFERT, M.; SILVEIRA, T. Mecanismos de tolerância da variedade de milho "saracura" (brs 4154) ao alagamento. Revista Brasileira de Milho e Sorgo, Sete Lagoas, v.1, n.1, p.41-52, 2002.

ARAÚJO, P. M.; NASS, L. L. Caracterização e avaliação de populações de milho crioulo. Scientia Agrícola, Piracicaba, v.59, n.3, p.589593, jul./set. 2002.

BATISTA, C. U. N.; MEDRI, M. E.; BIANCHINI, E.; MEDRI, C.; PIMENTA, J. A. Tolerância à inundação de Cecropia pachystachya (Trec. Cecropiaceae): aspectos ecofisiológicos e morfoanatômicos. Acta Botanica Brasilica, Porto Alegre, v.22, n.1, p.91-98, 2008.

BRASIL. Ministério da Agricultura. Regras para análises de sementes. Brasília: SNAD/DNDV/CLAV, 2009.

CÂMARA, T. M. M.; BENTO, D. A. V.; ALVES, G. F.; SANTOS, M. F.; MOREIRA, J. U. V.; SOUZA JÚNIOR, C. L. Parâmetros genéticos de caracteres relacionados à tolerância à deficiência hídrica em milho tropical. Bragantia, Campinas, v.66, n.4, p.595-603, 2007.

CARVALHO, N. M.; NAKAGAWA, J. Sementes: ciência, tecnologia e produção. 4.ed. Jaboticabal: FUNEP, 2000. 588p.

CERWICK, S. F.; MARTIN, B. A. The effect of carbon dioxide on maize seed recovery after flooding. Crop Science, Madison, v.35, n.4, p.1116-1121, 1995.

CHEN, H.; QUALLS, R. G.; MILLER, G. C. Adaptative responses of Lepidium latifolium to soil flooding: biomass allocation, adventitious rooting, aerenchyma formation and ethylene production. Environmental and Experimental Botany, Oxford, v.48, n.2, p.119-128, 2002. 
CONAB: Companhia Nacional de Abastecimento. Acompanhamento de safra brasileira: grãos, segundo levantamento, novembro 2013 / Companhia Nacional de Abastecimento. Brasília, DF: Conab, 2013.

CRAWFORD, R. M. M. Metabolic adaptations to anoxia. In: HOOK, D. D.; CRAWFORD, R. M.M (Ed.) Plant life in anaerobic enviromments. Ann Arbor, Michigan -1978, p.119-136.

CUSTÓDIO, C.; MACHADO NETO, N. B.; ITO, H. M.; VIVAN, M. R. Efeito da submersão em água de sementes de feijão na germinação e no vigor. Revista Brasileira de Sementes, Viçosa, MG, v.24, n.2, p.49-54, 2002.

DIAS, M. C. L. ; BARROS, S. R. Avaliação da qualidade de milho, Londrina: IAPAR. 1995, 43p.

DANTAS, B. F. Efeito do cálcio no desenvolvimento de aerênquimas e na atividade de enzimas de degradação e afrouxamento de parede celular em plântulas de milho (Zea mays L.) cv. Saracura BRS 4154 submetidas à hipoxia. 1999. 43f. Dissertação (Tese em fisiologia Vegetal) - Universidade Federal de Lavras, Lavras, 1999.

DANTAS, B, F.; ARAGÃO, C. A.; CAVARIANI, C.; NAKAGAWA, J.; RODRIGUES, J. D. Efeito da duração e da temperatura de alagamento na germinação e no vigor de sementes de milho. Revista Brasileira de Sementes, Viçosa, MG, v.22, n.1, p.88-96, 2000.

DANTAS, B. F.; ARAGÃO, C. A.; ALVES, J. D. Cálcio e o desenvolvimento de eaerênquimas e atividade de celulase em plântulas de milho submetidas a hipoxia. Scientia Agrícola, Piracicaba, v.58, p.251-257, 2001.

EMBRAPA - Empresa Brasileira de Pesquisa Agropecuária. Sistema brasileiro de classificação de solos. Brasília, DF: Embrapa-SPI; Rio de Janeiro: Embrapa-Solos, 2006. 306p.

EMYGDIO, B. M.; PEREIRA, L. R. Novas Cultivares, BRS Missões: nova cultivar de milho para a região sul do Brasil. Pesquisa Agropecuária Brasileira, Brasília, v.41, n.3, p.545-547, 2006.

FANCELli, A. L.; DOURAdO NETO, D. Produção de milho. 3. ed. Guaíba: Agropecuária, 2008. 360p.

FEPAGRO - Fundação Estadual de Pesquisa Agropecuária. Indicações técnicas para o cultivo de milho e sorgo no Rio Grande do Sul 2005/2006. Porto Alegre, 2005. 155p.
FERREIRA, J. M.; MOREIRA, R. M. P.; HIDALGO, J. A. F. Capacidade combinatória e heterose em populações de milho crioulo. Ciência Rural, Santa Maria, v.39 n.2, p.332339, 2008.

KHOSRAVI, G. R.; ANDERSEN, I. C. Pre-emergence flooding and nitrogen atmosfere effects on germinating corn inbreds. Agronomy Journal, Madison, v.82, n.2, p.495-499, 1990.

MOTERLE, L. M.; LOPES, P. C.; BRACCINI, A. L.; SCAPIM, C. A. Germinação de sementes e crescimento de plântulas de cultivares de milhopipoca submetidas ao estresse hídrico e salino. Revista Brasileira de Sementes, Viçosa, MG, v.28, n.3, p.169-176, 2006.

NASS, L. L.; PATERNIANI, E. Pre-breeding: a link between genetic resources and maize breeding. Scientia Agricola, Piracicaba, v.57, n.3, p.581-587, 2000.

OGLIARI, J. B.; SOUZA, R.; KAMPHORST, S. H.; GONÇALVES, G. M. B.; CANCI, A.; LAZZARI, L. Manejo e uso participativo de variedade crioula de milho como estratégia de conservação: experiência do núcleo de estudos em agrobiodiversidade no Oeste de Santa Catarina. Cadernos de Agroecologia, Porto Alegre, v.8, n.2, Nov.2013

PATERNIANI, E. NASS, L. L.; SANTOS, M. X. O valor dos recursos genéticos de milho para 0 Brasil: uma abordagem histórica da utilização do germoplasma. In: UDRY, C.W.; DUARTE, W. (Org.) Uma história brasileira do milho: o valor dos recursos genéticos. Brasília, DF: Paralelo 15, 2000. p.11-41.

PIMENTEL, C. Relações hídricas em dois híbridos de milho Sob dois ciclos de deficiência hídrica. Pesquisa Agropecuária Brasileira, Brasília, v.34, n.11, p.2021-2027, nov. 1999.

POPINIGIS, F. Fisiologia da semente. Brasília. 1985. 289p.

POTTKER, D. Recentes avanços no manejo químico do solo para a cultura do milho. In: SANDINI, I. E.; FANCELLI, A. L. Milho: estratégias de manejo para a cultura do milho. Guarapuava, 2000. p.63-87.

ROMERO, J. L.; MAGALHÃES, P. C.; ALVES, J. D.; DURÃES, F. O. M.; VASCONCELLOS, C. A. Efeito do cálcio sobre algumas características biofísicas emorfológicas de plantas de milho brs4154 submetidas ao alagamento do solo. Revista Brasileira de Milho e Sorgo, Sete Lagoas, v.2, n.3, p.21-33, 2003. 
SANGOI, L.; SILVA, P. R. F.; ARGENTA, G.; RAMBO, L. Desenvolvimento e exigências climáticas da planta de milho para altos rendimentos. Lages: Graphel, 2007. 95p.

SILVA, R. G.; GALVÃO, J. C. C.; MIRANDA, G. V.; OLIVEIRA, E. Identificação dos níveis e fontes de resistência aos enfezamentos do milho. Revista Brasileira de Milho e Sorgo, Sete Lagoas, v.1, n.3, p.18-29, 2002.

VAZ-DE-MELO, A.; SANTOS, L. D. T.; FINOTO, E. L.; DIAS, D. C. F. S.; ALVARENGA, E. M. Germinação e vigor de sementes de milho-pipoca submetidas ao estresse térmico e hídrico. Bioscience Journal, Uberlândia, v.28, n.5, p.687-695, 2012.

VELOSO, M. E. C.; DUARTE, S. N.; DOURADO NETO, D.; MIRANDA, J. H.; DA SILVA, E. C.; DE SOUZA, V. F. Doses de nitrogênio na cultura do milho, em solos de várzea, sob sistema de drenagem subterrânea. Revista Brasileira de Milho e Sorgo, Sete lagoas, v.5, p.382-394, 2006.
VISSER, E. J. W.; VOESENEK, L. A. C. J.; VARTAPETIAN, B. B.; JACKSON, M. B. Flooding andPlant Growth. Annals of Botany, London, v.91, p.107-109, 2003.

VITORINO, P. G.; ALVES, J. D.; MAGALHÃES, P. C.; MAGALHÃ̃ES, M. M.; LIMA, L. C. O.; OLIVEIRA, L. E. M. Flooding tolerance and cell wall alterations in maize mesocotyl during hypoxia. Pesquisa Agropecuária Brasileira, Brasília, v.36, n.8, p.1027-1035, 2001.

VON PINHO, R. G.; RAMALHO, M. A. P.; RESENDE, I. C. Reação de híbridos comerciais de milho às ferrugens polissora e tropical. Pesquisa Agropecuária Brasileira, Brasília, v.36, n.3, p.439-445, 2001. 